\title{
SINERGIA
}

REVISTA DO INSTITUTO DE CIÊNCIAS ECONÔMICAS, ADMINISTRATIVAS E CONTÁBEIS (ICEAC)

\section{ANÁLISE DO NÍVEL DE TREINAMENTO DOS TRABALHADORES DA CONSTRUÇÃO CIVIL NA CIDADE DE MONTEIRO-PB}

\author{
JOÃO MORAES SOBRINHO \\ FÁBIO JOSÉ DE SOUSA MEDEIROS"
}

\begin{abstract}
RESUMO
A construção civil é uma área que apresenta grande importância econômica para o país. A área de construção requer os mais variados tipos de conhecimentos e competências técnicas e conceituais. $\mathrm{O}$ objetivo deste trabalho foi analisar o nível de treinamento dos trabalhadores da construção civil em Monteiro-PB. A relevância do trabalho reside no fato do treinamento ser uma estratégia que pode agregar vantagem competitiva às organizações e estimular a redução de possíveis patologias, bem como ajudar a reduzir custos e retrabalhos. A pesquisa, delineada como estudo de campo, utilizou entrevistas com gestores da construção da cidade de Monteiro-PB e formulários aplicados junto aos trabalhadores do nível operacional, para um diagnóstico mais preciso. Os dados foram coletados na primeira quinzena de março de 2016. Os dados apontam para a falta de capacitação, treinamentos e estímulos ao desenvolvimento para os trabalhadores da construção na região. Conclui-se que os gestores de obras de Monteiro-PB ainda não dão o devido valor ao desenvolvimento de competências que poderão conduzir suas empresas a maiores níveis de competitividade e que os trabalhadores ainda carecem de estratégias para sua formação e desenvolvimento profissional, o que pode, a médio prazo, afetar a sua empregabilidade.
\end{abstract}

PALAVRAS-CHAVE: Treinamento. Construção. Avaliação.

\section{ABSTRACT}

The construction field is an area that has great economic importance for the country. The construction field requires several kinds of technical and conceptual knowledge and skills. The study aimed to map the level of training of construction workers in Monteiro-PB. The relevance of the work relies in the fact that the training is a strategy that can add competitive advantage to organizations and encourage the reduction of diseases and help reduce costs and rework. The research, designed as field study, used interviews with municipal construction managers and forms applied at the operational level workers, to a more accurate diagnosis. Data were collected in the first half of March 2016. The data point to the lack of training and incentives for the development for construction workers in the area. It is concluded that Monteiro's construction managers do not give due importance to the development of skills that will lead their companies to higher levels of competitiveness and workers still need training strategies and professional development, which may, in the medium term affect their employability.

KEYWORDS: Training. Construction. Evaluation.

Recebido em: 20-02-2017 Aceito em: 16-05-2017

\section{INTRODUÇÃO}

A Construção Civil é uma área bastante ampla, chegando a abranger diversas atividades de produção em obras dos mais diversos portes. Algumas atividades que estão inclusas referentes ao planejamento e projeto, manutenção, restauração e execução de obras em diferentes segmentos, tais como edifícios, portos, aeroportos, túneis, instalações prediais, obras de saneamento, de fundações e de terra em geral (SAMARCOS et al, 2000).

Um setor que abrange diversas áreas com conhecimentos específicos, tais como a área de instalações elétricas e hidrossanitárias, fundações, telhados, alvenarias, concreto, revestimento, dentre outros, que correspondem a área da construção civil. Suas ideias são representadas através de projetos, os quais são elaborados por um ou mais profissionais da área. Terminada a elaboração dos projetos, os mesmos passam por um estudo de viabilidade para evitar que ocorra algum erro na hora da execução da obra. Realizado o planejamento, parte-se para a etapa da execução, na qual começa a se pôr em prática tudo o que está idealizado. Exige-se auxílio de uma equipe para realizar o trabalho operacional e poder, assim, chegar ao

\footnotetext{
Mestre em Administração pelo Programa de Pós-Graduação em Administração da Universidade Federal da Paraíba. Professor do Instituto Federal de Educação, Ciência e Tecnologia da Paraíba.

"Graduado em Tecnologia em Construção de Edifícios pelo Instituto Federal de Educação, Ciência e Tecnologia da Paraíba
} 
resultado final esperado, que é sua obra concluída e bem executada. Para a Secretaria da Receita Federal do Brasil (2015), uma obra de construção civil se define como a construção, a demolição, a reforma, a ampliação de edificação ou qualquer outra benfeitoria agregada ao solo ou ao subsolo.

O setor da construção civil está voltado para profissionais de níveis de escolaridade bem distintos, variando de profissionais sem instrução até profissionais de nível superior. Para a Associação Brasileira da Indústria de Materiais da Construção - ABRAMAT (2007), o trabalhador necessita se submeter a um processo de formação escolar, que pode contribuir, diretamente, na formação profissional de cada um. O perfil do trabalhador da Construção Civil pode ser analisado sob dois diferentes pontos de vista: o social, que aborda aspectos referentes a sexo, escolaridade, faixa etária e vulnerabilidade social; e o econômico, que aborda aspectos de rotatividade, renda, nível de emprego e vulnerabilidade econômica (FERREIRA JUNIOR, 2012). A partir da análise deste núcleo de pensamento, constata-se que, para esses investimentos gerarem lucros aos investidores, o projeto final tem que agradar ao público-alvo (clientes). Um ponto forte que influencia diretamente no resultado final de uma obra de engenharia é a qualidade da sua mão de obra. Profissionais da área com a qualificação requerida pelas empresas são escassos no mercado da construção civil no país. Nesse sentido, Regino (2010) considera que se vivencia uma conjuntura de construção civil brasileira, com carência de profissionais qualificados, desde vigias até projetistas e engenheiros de produção. Essa linha de pensamento é muito bem destacada por Blanco (2007), quando a autora ironiza argumentando que o setor da Construção Civil no Brasil foi construído artesanalmente pelas mãos de operários analfabetos e que sequer possuíam alguma qualificação técnica. A autora ainda ressalta que o país vem, durante anos, pagando o preço pela falta de capacitação de trabalhadores. Para Mendes (2010), o problema de mão de obra já se intensificou e a escassez é geral. Paralelamente, Mendes (2010) também relata que a disputa setorial por operários já afeta a dinâmica da gestão de incorporadoras e construtoras, inclusive no setor financeiro.

A Sinduscon de Mato Grosso faz uma ressalva à escassez de mão de obra, enfatizando que a falta de mão de obra é sistêmica no setor, com escassez desde operários menos qualificados como serventes até os mais qualificados, como mestres de obras e engenheiros. Por esse motivo, as empresas estão optando por formar seus próprios profissionais (CICHINELLI; REIS, 2010).

Bellei (2010) e McKinsey (1998) também apontam para a falta de mão de obra, assinalando que a produtividade da mão de obra do setor de construção é de apenas $32 \%$ da atingida pela mesma indústria nos Estados Unidos.

Eficiência é o processo pelo qual a organização maximiza seus fins com uso mínimo de recursos. Eficiência diz respeito a método, a modo certo de fazer as coisas. É definida pela relação entre produtos produzidos em relação aos recursos consumidos. Uma empresa eficiente é aquela que consegue otimizar seu volume de produção com o menor dispêndio possível de recursos. A medida de eficiência pode ser representada por meio de indicadores (CATELLI, 2001). O índice de eficiência operacional dos trabalhadores da construção está diretamente ligado ao nível de produtividade do mesmo. Souza (2005) argumenta que esse indicador está ligado totalmente à ineficiência e ao desperdício. Para o autor, a produtividade dentro da área da construção seria a relação feita com a produção, ou seja, a faculdade de produzir. Ainda segundo Souza (2006), a produtividade da mão de obra pode ser definida como a eficiência na transformação dos esforços dos trabalhadores em produtos de construção, a obra ou suas etapas.

Outro detalhe importante relativo à ligação entre produtividade e melhoria na eficiência operacional está bem ressaltado por Limmer (2010), quando ele afirma que uma gestão da qualidade resulta, obrigatoriamente, em melhoria de produtividade, tendo em vista que a mão de obra terá de ser treinada para realizar as tarefas com maior eficiência e cada integrante da equipe de trabalho terá melhor definida sua função no sistema de produção, levando cada membro a conscientizar-se do papel que desempenha no sistema.

Considerando o dinamismo atual da construção civil, sua mão de obra presente no canteiro não pode mais contar somente com o aprendizado empírico (REGINO, 2010). A colocação do autor alerta para a necessidade de o profissional de construção se manter sempre atualizado com a evolução de sua profissão.

Diante do exposto, propõe-se o seguinte problema de pesquisa: "Qual o nível de treinamento dos trabalhadores da construção civil em Monteiro"? Dessa forma, o objetivo deste trabalho é analisar o nível de treinamento dos trabalhadores da construção civil em Monteiro-PB. Para atingir tal objetivo, buscou-se identificar os incentivos oferecidos pelas organizações para capacitação da sua força de trabalho, analisar a frequência a que os trabalhadores são submetidos a treinamentos e verificar as estratégias utilizadas para capacitação da força de trabalho.

Dentro desse contexto, é de fundamental importância analisar o nível de qualificação da mão de obra da construção civil, tendo em vista que o nível de capacitação do trabalhador da construção afeta diretamente o resultado da obra, a satisfação do cliente e o nível de competitividade das organizações envolvidas. Uma mão de obra eficiente é algo a ser mensurado pelos profissionais do mercado de trabalho. Essa mensuração é muito importante, já que, com a inovação em vários setores da construção, profissionais bem qualificados estão cada vez mais escassos no mercado de trabalho. É indiscutível que uma mão de obra eficiente pode evitar riscos mais elevados de futuras patologias nas obras de engenharia (LIMMER, 2010). 


\section{REFERENCIAL TEÓRICO}

Este referencial teórico está subdividido em duas partes distintas. A primeira parte aborda um breve panorama da construção civil no Brasil e no estado da Paraíba. Em seguida, o referencial se debruça sobre alguns aspectos conceituais relevantes pertinentes ao treinamento e ao desenvolvimento de pessoal, com ênfase no ciclo de treinamento e sua influência nos resultados da construção.

\subsection{Um breve panorama da construção civil no Brasil}

Desde os primórdios, a indústria da construção civil apresenta grande importância para o crescimento do Brasil, não só em nível social, com grande absorção de mão de obra por esse setor, mas também no âmbito econômico, com a grande parcela na participação no produto interno bruto, resultando numa interferência benéfica na balança comercial e no controle da inflação (PASSOS et al, 2012). Para o autor, um dos principais fatores que compõe a economia de um país é a construção civil. Obras paradas refletem negativamente no atual cenário nacional, e sabe-se que o setor está em momento delicado.

O PIB é um importante indicador econômico para um país. Ele é caracterizado pela soma dos bens e serviços produzidos no país, descontando-se as despesas com os insumos utilizados no processo de produção (COLLETTI, 2006). Para Passos et al, (2012) um dos principais indicadores que medem a saúde de uma atividade econômica é o PIB. Souza (2006) cita que a construção civil contribui diretamente para a economia do país quando o governo investe em obras públicas. Esse investimento incentiva a geração de novos empregos diretos e gastos com a compra de materiais de construção. Na visão de Souza e Ripper (2009), o setor da construção civil no Brasil é uma área do conhecimento humano em constante evolução, seja do ponto dos materiais utilizados para se construir, seja das técnicas construtivas empregadas.

A indústria da construção civil ocupa um papel de destaque na economia brasileira, representando uma fração expressiva do PIB brasileiro. Portanto, uma gestão qualificada de mão de obra é importante também para a economia do país. A Câmara Brasileira da Indústria da Construção - CBIC indica que o macrosetor da construção responde por mais de $18 \%$ da riqueza nacional (SOUZA, 2006). Tendo em vista que a construção civil é uma área que vem se desenvolvendo muito ao longo dos anos, dados da pesquisas realizadas pela Pini (2014) indicam que, no Brasil, a construção civil teve um crescimento de $74,25 \%$ nos últimos vinte anos, um avanço médio de $2,82 \%$ anualmente. $O$ setor de construção civil tem participação considerável na economia brasileira, representando cerca de 5,7\% de participação em 2010 (IBGE, 2010). Dados como os citados acima demonstram como a indústria da construção tem um papel fundamental no setor nacional da economia brasileira. Seus serviços movimentam números bastante elevados de recursos por ano no Brasil.

\subsubsection{Construção civil na Paraíba}

A Paraíba é um dos vinte e sete estados que compõem o território brasileiro. Possui 223 municípios e a sua capital é João Pessoa, localizada na região litorânea do estado. É composta por uma área de aproximadamente $56.469,744 \mathrm{~km}^{2}$ e uma população de aproximadamente 3.972 .202 habitantes, com uma densidade demográfica de 66,77 habitantes $/ \mathrm{km}^{2}$ (IBGE, 2015). A cidade, que foi abordada nessa pesquisa, foi a cidade de Monteiro, localizada no Cariri Paraibano, que fica a uma distância de aproximadamente $312 \mathrm{~km}$ da capital, João Pessoa. Segundo o Instituto Brasileiro de Geografia e Estatística - IBGE (2016), Monteiro possui uma área territorial de aproximadamente $986,356 \mathrm{~km}^{2}$ e uma população de aproximadamente 30.852 habitantes.

No quadro abaixo, são apresentados alguns dados referentes à última pesquisa realizada pela Pesquisa Anual de Indústria da Construção-PAIC, no ano de 2013, sobre o setor da construção civil no estado da Paraíba:

QUADRO 1 - Empresas da construção civil na Paraíba.

\begin{tabular}{|c|c|}
\hline Número de empresas ativas & 1.005 \\
\hline Número de pessoas ativas & 38.204 \\
\hline Número aproximado de pessoas por empresas & 38 \\
\hline \multicolumn{2}{|c|}{ FONTE: Adaptado de IBGE (2016). }
\end{tabular}

FONTE: Adaptado de IBGE (2016).

\subsection{Treinamento e desenvolvimento de pessoas}

Falar de recursos humanos e não falar de treinamento é temerário no setor de construção civil. O treinamento de recursos humanos é talvez 0 aspecto primordial para a formação de qualquer profissional. (CARVALHO; NASCIMENTO\& SERAFIM, 2012). Os autores ainda completam falando que esta ação deve estar presente no dia a dia de toda organização, ajudando as empresas a adquirir novos conhecimentos e se aprimorando no seu determinado serviço. Milkoviche e Boudreau (2013) reforçam a ideia da importância do treinamento de pessoal, ressaltando que o treinamento fortalece um processo de desenvolvimento de 
competências dos empregados em seus papéis funcionais.

Carvalho, Nascimento e Serafim (2012) reforçam a importância de se ter um programa de treinamento permanente nas empresas. O treinamento é umas das principais funções para o sistema de recursos humanos, pois é considerada uma das etapas finais do processo seletivo de cada cargo. $O$ treinamento não só tem por objetivo capacitar alguém para desempenhar determinado processo ou função mas, também, ajudá-las a serem mais importantes para a organização. Chiavenato (2010) reforça as teses citadas acima, quando expõem seus ideais que, quando explicando o treinamento como um processo pelo qual a empresa apenas se preocupa em preparar o colaborador para executar uma tarefa específica de maneira excelente, ficou no passado. Diante atualidade, o termo é considerado um meio de desenvolver competências nas pessoas, tornando-as mais produtivas, criativas e inovadoras. Consequentemente, elas se tornam mais valiosas, produtivas e lucrativas para a empresa.

A importância de treinar um indivíduo ganha uma maior contextualização com o relato de Milkovich e Boudreau (2013, p. 340): "Existem evidências crescentes e uma maior consciência de que o treinamento e a educação são investimentos estratégicos para a prosperidade nacional." Seewald (2004) afirma que a maioria dos acidentes que acontecem em uma empresa ocorrem na primeira semana de trabalho. Isso é decorrente da falta de adaptação e manejo do exercício da função do trabalhador. A desqualificação de mão de obra resulta diretamente da falta de interesse dos donos das organizações em realizar ações, como treinamentos, para garantir uma melhor produtividade e qualidade em suas obras (FARIA, 2011).

Treinamento é um processo sistemático para promover a aquisição de habilidades, regras, conceitos ou atitudes que resultem em uma melhoria da adequação entre as características dos empregados e as exigências dos papéis funcionais (MILKOVICH \& BOUDREAU, 2013). Já Chiavenato (2009) relata um conceito mais completo sobre o termo treinamento quando diz que é tratado como um processo do tipo educacional que foca o curto prazo, sendo aplicado de maneira sistemática e organizada, por meio do qual as pessoas aprendem conhecimentos, habilidades e competências em função de um objetivo definido. Carvalho, Nascimento e Serafim (2012) apresentam um conceito que treinamento é um processo interligado à educação, despertando dons, aptidões e capacidades que, na maioria das vezes, encontram-se ocultas. Como vimos acima, existem três conceitos básicos distintos definindo a palavra treinamento. Cada um dentro da sua visão sobre o termo, mas não deixando de definir bem o seu significado. Chiavenato (2010) foca bem isso, quando fala que o termo treinamento pode apresentar inúmeros significados. $O$ autor detalha um pouco do processo desse conceito, quando fala que, no passado, especialistas tinham o treinamento como um meio para adequar cada pessoa a seu determinado cargo, como se fosse um preenchimento de cargo. E mais recentemente, esse conceito foi ampliado, considerando o treinamento como um meio para alavancar o desempenho no cargo. $\mathrm{O}$ argumento seguinte evidencia a importância de uma empresa ter profissionais bem treinados. O treinamento tem por objetivo atingir metas. Se alguém treina para algo, é porque pretende atingir um resultado final. Carvalho, Nascimento e Serafim (2012) afirmam que o treinamento sobrevém de uma adoção de metas que contribuem para a formação e determinação de resultados a serem alcançados por uma unidade de treinamento de uma empresa. Esses objetivos de capacitação refletem as mudanças econômicas, sociais e tecnológicas do mercado em que a empresa está operando. Os autores ainda relatam que os objetivos podem ser divididos em dois grupos. Os quantificáveis e os não quantificáveis. Os quantificáveis é o grupo de metas de treinamento que podem ser mensuradas. Englobando tarefas como treinar a força de vendas, aumentar o número de unidades, diminuir custos operacionais e administrativos, entre outros. Os não quantificáveis é o grupo o qual as metas de treinamento que não podem ser mensurados, como por exemplo: modificar o comportamento do profissional treinado, desenvolver aptidões de liderança, desenvolver o espírito de trabalho em equipe, entre outros.

Para Milkovich e Boudreau (2013), as metas eficientes são aquelas que podem ser mensuradas, estabelecendo datas limites bem específicas. Os autores ainda explanam que os objetivos mudam constantemente à medida que os programas de treinamento são introduzidos na organização, por causa das novas informações que vêm à tona para serem utilizadas nas próximas etapas das necessidades que a empresa precisa suprir.

Preparar pessoas para uma execução imediata às tarefas dos cargos; proporcionar as pessoas não apenas para os cargos desempenhados no presente, mas alguns que possam aparecer no futuro; mudanças de atitudes criando um clima mais satisfatório entre as mesmas (CHIAVENATO, 2009). Além dos objetivos citados acima, um bom treinamento é aquele que o capital humano das organizações gera um maior lucro para a empresa. Já que o sucesso de uma empresa é composto pelo bom desempenho do mais simples operário até o seu principal executivo, o treinamento torna-se algo vital para o sucesso do negócio.

Faria (2011) completa falando que os principais pontos a serem atingidos em um treinamento são a formação profissional, a especialização e a reciclagem. Dentro de um canteiro de obras existem diferentes trabalhadores e nem todos receberam o mesmo tipo de treinamento. 


\subsubsection{Tipos de treinamento}

Após se ter certa noção dos objetivos em se treinar alguém, deve-se compreender que não existe um padrão de treinamento. Nem todo mundo aplica o mesmo método para treinar uma equipe ou um indivíduo.

Em conjunto com os diferentes tipos de treinamentos, existem diferentes técnicas a serem utilizadas. Dentre elas, a de leitura, instrução programada, treinamento em classe, computer-based training (CBT) e e-learning (CHIAVENATO, 2010).

Embasando esse pensamento, deve-se entender que o que vai definir o tipo de treinamento adotado é o tipo de função na qual o trabalhador estará designado a operar.

Algumas empresas usam filmes que mais se aproximem da realidade do dia a dia da empresa, outras criam projetos desafiadores para grupos; outras utilizam o método de ouvir cada profissional, entendendo em que cada um se sai melhor (MILKOVICH \& BOUDREAU, 2013). Ressalte-se que o treinamento fica dividido em treinamento da parte operacional e o treinamento da gerência.

O treinamento da parte operacional está voltado para os trabalhadores que ficaram a cargo de executar tarefas, ou seja, estão ligados no nível operacional, e o mesmo pode ser 100 vezes mais extenso do que o da área gerencial. $\mathrm{E}$ o da área gerencial fica reservado para as pessoas que desempenham um papel executivo (MILKOVICH \& BOUDREAU, 2013).

\subsubsection{Ciclo de treinamento}

Todo treinamento passa por um sistema e um ciclo, o qual tem inicio, meio, fim e uma resposta positiva ou negativa do que se foi aplicado. Chiavenato (2009) descreve que o sistema possui exatamente quatro etapas: Entrada, Processo, Saída e Retroação ou Feedback, representadas na figura 1, a seguir:

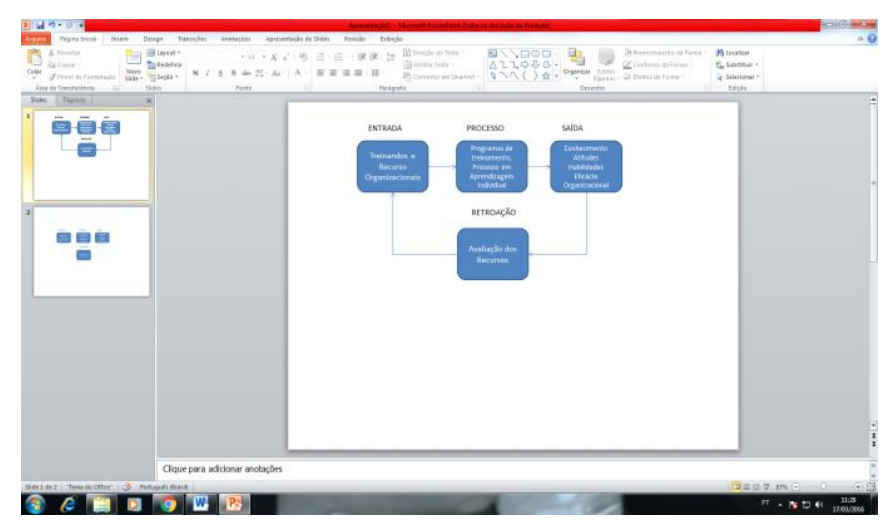

FIGURA 1 - Treinamento como um sistema FONTE: Adaptado de CHIAVENATO (2009).

$\mathrm{Na}$ entrada, ficam os treinandos, os recursos organizacionais, as informações, os conhecimentos, entre outros. O processo trata da parte que abrange os processos de ensino, programas de treinamento e aprendizagem individual, entre outros. A saída pode ser representada como o pessoal habilitado, competências, conhecimentos, sucesso organizacional; retroação, por sua vez, é a avaliação dos procedimentos e resultados que o treinamento proporcionou através de meios informais ou pesquisas sistemáticas. O treinamento pode ser visto como um processo contínuo, semelhante a um ciclo que tende a sempre estar se renovando.

Pode-se analisar que o ciclo de treinamento é um sistema em que todos os fatores interagem entre si, ou seja, todas as suas etapas estão interligadas. Seguindo sempre o sistema de entrada e saída de cada etapa, sendo a saída da avaliação dos resultados do treinamento como sua etapa mais importante, tendo em vista que é nela que se afere se o que foi treinado sai conforme o esperado. A primeira etapa do ciclo é uma das etapas fundamentais para o ciclo de treinamento, tendo em vista que é nela que serão abordados todos os pontos que serão necessários a serem atendidos (CHIAVENATO, 2009). O autor relata que no ciclo a primeira etapa é um levantamento das necessidades ou diagnóstico a ser realizado, independente do tempo nas quais elas ocorram, presente, passado ou futuro. Decorrente a primeira etapa, é realizado um desenho do esquema de como será o programa de treinamento. Um projeto e programação na qual esse programa tem como objetivo atender a todas as necessidades que foram detectadas na primeira etapa. Seguindo o ciclo, surge a fase de execução ou implementação de tudo que foi elaborado na fase anterior, tendo por objetivo colocar em prática tudo que fora projetado. Tomando o devido cuidado para conduzir tudo de maneira ordenada e eficaz (CHIAVENATO, 2009).

Por fim, Carvalho, Nascimento e Serafim (2012) descrevem a avaliação de um treinamento como um passo importante para o sucesso do programa, tendo em vista que é a parte que se analisa o que fora treinado. No que diz respeito ao que fora treinado, é necessário uma interligação entre certos pontos como: o 
que será transmitido; quem receberá; quando ocorrerá; onde será; como se processará o treinamento.

A avaliação do treinamento na construção civil tem a finalidade de garantir que a qualidade da obra será atendida, tal como os serviços que estão sendo executados conforme o que foi treinado. Nesse método, é primordial que tudo saia conforme foi definido pelo planejamento do treinamento a ser realizado. Essa é a etapa que finaliza o processo de treinamento, vindo a avaliar a eficiência da mão de obra treinada, considerando se o treinamento veio a produzir as mudanças desejadas no comportamento dos funcionários e se os resultados estão de acordo com os objetivos empresariais (CHIAVENATO, 2009).

\subsubsection{NBR ISO 10015/2001 - Gestão da qualidade - Diretrizes para treinamento}

Existem normas técnicas que oferecem diretrizes para o desenvolvimento do treinamento. Dentre elas, se pode destacar a NBR ISO 10015/2001 - Gestão da qualidade - Diretrizes para treinamento, cuja função é fornecer orientações que possam assessorar uma organização a identificar e analisar as necessidades de treinamento, projeto, planejamento e execução, além de avaliar seus resultados e monitorar e melhorar o processo de treinamento, de modo a atingir seus objetivos (ABNT, 2001).

A ABNT - Associação Brasileira de Normas Técnicas é uma entidade nacional de normalização, na qual os conteúdos das normas são regidos por um comitê brasileiros e dos Organismos de Normalização Setorial.

As diretrizes dessa norma têm como objetivos a melhoria contínua de uma organização, como por exemplo o desempenho da mão de obra, incluindo as mudanças no mercado, sempre buscando inovações da parte de clientes e de tecnologias.

Essa norma é composta pelas seguintes diretrizes:

- Treinamento: um processo em quatro estágios;

- Definição das necessidades de treinamento;

- Projeto e planejamento do treinamento;

- Execução do treinamento;

- Avaliação dos resultados do treinamento;

- Monitoração e melhoria do processo de treinamento.

A questão da qualidade no setor da construção civil vem recebendo uma atenção crescente, ganhando espaço em publicações e eventos, servindo de iniciativas para empresas e fazendo parte integrante dos procedimentos das construtoras. Assim, o enfoque da gestão da qualidade tem evoluído, passando de uma visão corretiva, que se baseia na inspeção, para uma visão voltada a ações preventivas em todas as etapas do processo (OLIVEIRA, 2013).

\subsection{Patologias da construção como reflexos de uma força de trabalho pouco qualificada}

Patologias nas edificações são anomalias ou possíveis problemas nos edifícios; as mesmas podem surgir ou serem adquiridas congenitamente, ou seja, pelo processo de execução da obra, ou mesmo pelo uso de materiais inadequados, uma má execução de serviço, uma compreensão equivocada do projeto e até ao longo da vida da estrutura (FRANÇA ET AL, 2011).

França et al (2011) explanam bem o significado de patologia destacando a origem grega do termo páthos que significa doença e logos, que significa estudo. Os mesmos ainda completam que o termo patologia é bastante amplo, tendo em vista que pode ser utilizado em diversas áreas da ciência, para denominar objetos de estudo, variando de acordo com o ramo de atividade.

As patologias variam de acordo com o ramo de atividade que está inserida, nesse caso, o ramo envolvido é o da construção civil. Reforçando o argumento acima, Souza (2008) expõe que o termo patologia das construções vem sendo usado rotineiramente em uma comparação as enfermidades da área medicinal, com o intuito de identificar os danos e erros ocorridos em construções.

Para Souza e Ripper (2009), o homem se preocupa com as estruturas de suas construções desde os primórdios de sua civilização, independente do tipo de obra que esteja sendo realizada. Os mesmos ainda relatam que é quase inevitável que surjam falhas involuntárias e casos de imperícias nas obras. Esses, muitas vezes, são fatores determinantes para que as estruturas apresentem um desempenho bem abaixo do esperado.

O surgimento de patologias é quase inevitável. Mas as mesmas podem ser controladas e evitadas. Tudo irá depender do controle e cuidados que o profissional terá ao executar as atividades construtivas e ao material que o mesmo escolher.

Oliveira (2013) defende que a qualidade final do produto depende muito da qualidade empenhada em cada etapa da obra.

É possível perceber que as patologias surgem de uma má execução ou má aquisição de materiais e necessita-se de algo para evitar isso. Limmer (2010) afirma que a mão de obra terá de ser treinada para realizar as tarefas com uma maior eficiência em seu resultado final. 


\section{METODOLOGIA}

A seguir, o percurso metodológico da pesquisa será apresentado.

\subsection{Caracterização da pesquisa}

O presente trabalho apresenta natureza descritiva e abordagem qualitativa e quantitativa. Foi delineado como um estudo de campo. Estudos descritivos se propõem a analisar e descrever a dinâmica de determinados fenômenos, descrevendo situações e acontecimentos (SAMPIERI, COLLADO; LUCIO; 2006).

\subsection{Contexto e sujeitos de pesquisa}

O contexto da pesquisa foi o próprio local de trabalho dos trabalhadores. Os elementos selecionados (sujeitos) para investigação foram 3 (três) gestores de obras e 9 (nove) profissionais de nível operacional. A seleção desses dois grupos foi realizada com o intuito de se comparar as visões e aumentar a validade e confiabilidade das respostas. A amostra foi não probabilística e escolhida por acessibilidade. O número adotado se deu em função do critério da saturação teórica.

\subsection{Estratégia de coleta e análise dos dados}

Os dados foram coletados entre a primeira e a segunda semana do mês de março de 2016. Para os profissionais responsáveis pelas obras, foi utilizada a técnica da entrevista semiestruturada com o intuito de identificar e analisar as práticas que as empresas ou obras adotam para sua força de trabalho. Posteriormente, formulários foram aplicados junto a 09 profissionais de nível operacional de 03 obras diferentes da cidade de Monteiro-PB para analisar a sua própria percepção acerca das práticas e incentivos relacionados ao treinamento em seus próprios locais de trabalho. O formulário continha 10 questões que abrangeram aspectos relacionados ao tipo de treinamento oferecido, a frequência em que o trabalhador era submetido a treinamentos, as estratégias utilizadas para capacitação da força de trabalho e os tipos de incentivos que as empresas ou construções adotavam para incentivar a qualificação de seu pessoal. As entrevistas foram analisadas com base na técnica da análise de conteúdo, técnica consagrada por Bardin (2011) para análise e categorização de dados verbais. O autor define a análise de conteúdo como uma técnica de análise das comunicações que toma como base o texto, como material primário de análise. Os formulários continham questões fechadas e foram analisados a partir de tabulação e estatística descritiva.

\section{ANÁLISE E DISCUSSÃO DE RESULTADOS}

O objetivo deste tópico é descrever e analisar os dados coletados acerca do nível de treinamento dos trabalhadores da construção civil que atuam na cidade de Monteiro-PB. Foram utilizados dois métodos na pesquisa de campo, o questionário e a entrevista.

\subsection{Análise dos questionários}

Os gráficos a seguir mostram os dados obtidos por meio dos questionários preenchidos pelo autor, com as respostas dadas pelos trabalhadores.

O gráfico 1 mostra dados obtidos em relação ao gênero dos trabalhadores. Observou-se que $100 \%$ dos entrevistados eram homens. Tendo em vista que as obras visitadas eram de pequeno porte, os trabalhadores que se encontravam no local se limitavam a pedreiros e serventes, funções que requerem o uso de força física. Por esse motivo esse índice já era esperado.

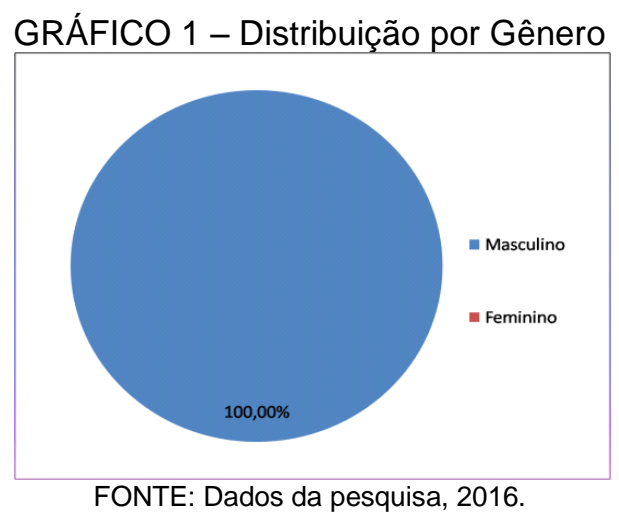


No Gráfico 2, constataram-se alguns pontos importantes para a pesquisa. Em primeiro lugar, a maioria dos entrevistados tem idade entre 41 e 50 anos, mostrando uma classe de trabalhadores em tese, experiente, tendo em vista que todos disseram que trabalham desde a infância. Não foi encontrado nenhum trabalhador de menor idade entre eles. Outro ponto foi que a maioria dos operários que participaram da pesquisa eram semianalfabetos, limitando-se a escrever o próprio nome e/ou tinham uma fraca leitura, aspecto verificado quando os mesmos recebiam os termos de autorização. Já os encarregados partilhavam de uma boa leitura, mas limitavam-se a um ensino fundamental incompleto, fator bastante negativo, tendo em vista que Abramat (2007) enfatiza que é necessário que cada trabalhador passe por uma formação escolar. Essa diversidade nos perfis dos trabalhadores corrobora a visão de Ferreira Junior (2012), quando o mesmo afirma que o perfil do trabalhador da Construção Civil pode ser analisado sob diferentes pontos de vista sociais como sexo, escolaridade e faixa etária.

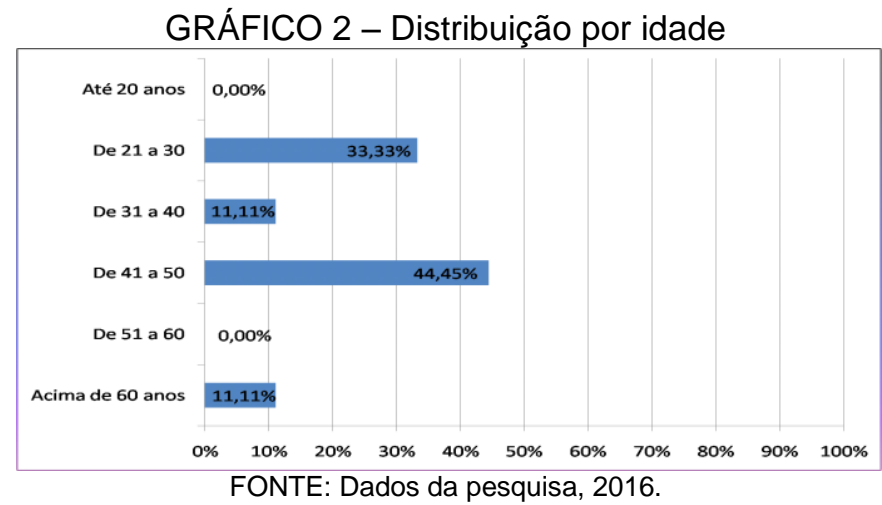

No gráfico 3 , que apresenta a faixa salarial dos trabalhadores, notou-se uma certa desvalorização na mão de obra da cidade, tendo em vista que mais de $50 \%$ deles recebem pouco mais de um salário mínimo. Os $44,44 \%$ que ultrapassam os $R \$ 1.000,00$ mensais relataram que não chegam a receber $R \$ 1.500,00$ por mês. Esse fator é bastante negativo, pois a construção civil é um setor que costuma absorver um número alto de mão de obra, além de contribuir diretamente na economia do país, conforme Passo et al (2012).

GRÁFICO 3 - Renda média

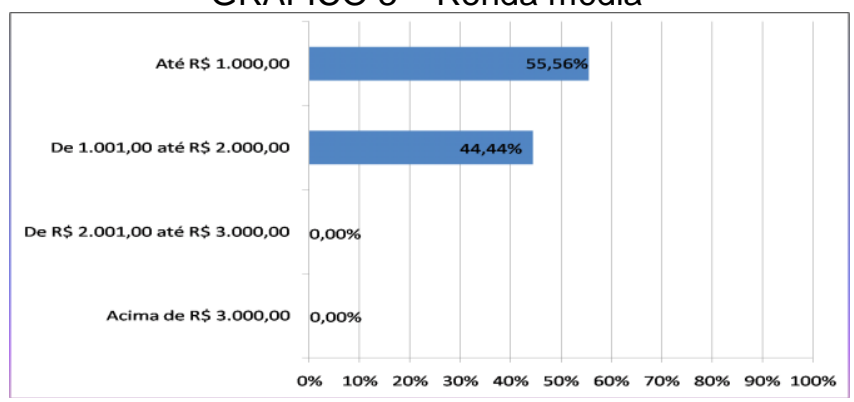

FONTE: Dados da pesquisa, 2016.

No gráfico 4, nota-se um dado bastante alarmante: nenhum dos entrevistados possuía vínculo de trabalho formal. Todos trabalham de forma autônoma, por tempo indeterminado, até que seus serviços não sejam mais necessários. Outro dado negativo em relação a essa questão foi que a maioria relatou que além de não possuir carteira assinada pelos empregadores, não existe contrato formal e o acordo é feito apenas de forma verbal entre patrão e empregados, não garantindo nenhuma segurança ao trabalhador.

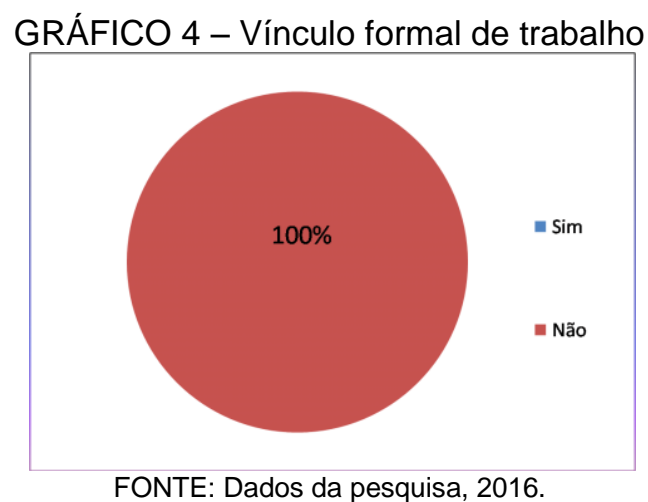


No resultado do gráfico 5 , mais um ponto negativo, em que apenas um dos entrevistados afirmou ter participado de algum curso formal para exercer sua função. O mesmo disse que fez um curso de pedreiro na cidade de Sertânia-PE.

Um mal profissional pode comprometer toda uma obra. Seewald (2004) relata que o treinamento da mão de obra reflete diretamente no processo construtivo de uma obra.

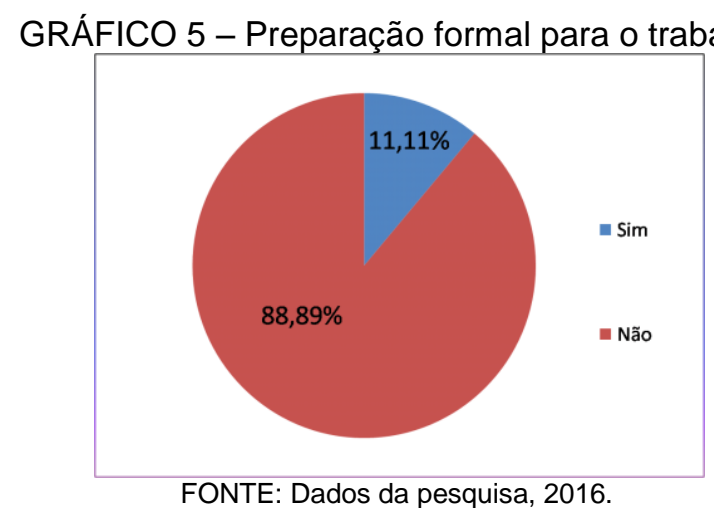

No gráfico 6, evidencia-se que os trabalhadores não participam, com frequência, de treinamentos. Fato bastante negativo, tendo em vista que a construção civil é uma área bastante ampla e complexa. Delimitar seus serviços a uma só classe de profissionais seria quase que impossível, chegando a soar como utópico. Em uma obra, um fator que tem um peso considerável é o tempo. Conforme Araújo (2010), quanto menos tempo se leva para concluir uma obra, mais rápido se pode iniciar outra e assim aumentar os lucros dos investidores. Tempo e dinheiro são fatores inversamente proporcionais na construção civil. Junto a esses dois fatores, existe também outro fator que completa essa relação: a qualidade.

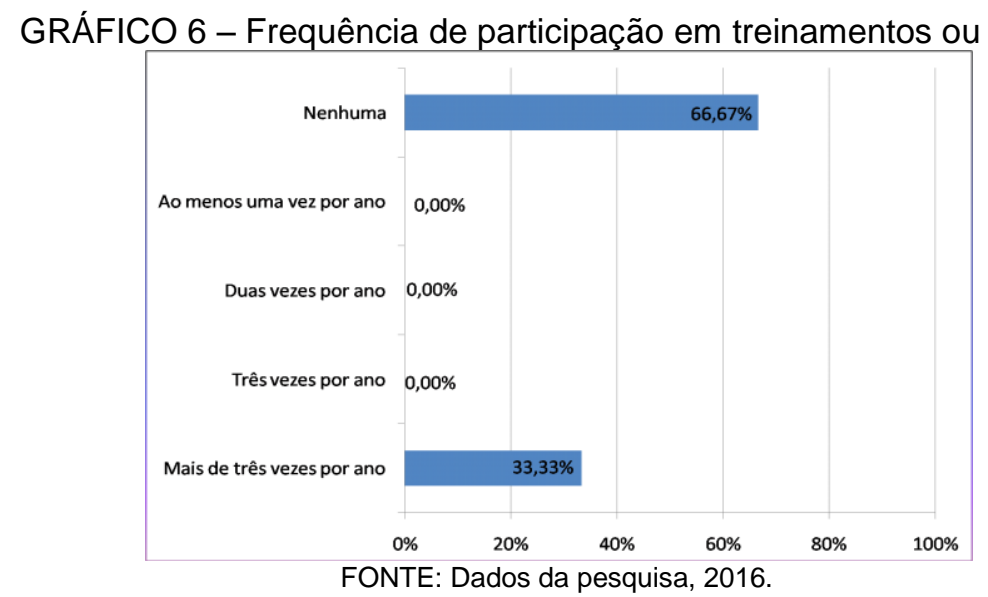

A desqualificação de mão de obra resulta diretamente da falta de interesse dos donos das organizações em realizar ações, como treinamentos, para garantir uma melhor produtividade e qualidade em suas obras (FARIA, 2011).

Isso ficou bastante explícito nos dados do gráfico 7 , em que apenas em uma das três obras visitadas a empresa realiza algum tipo de treinamento. Os trabalhadores relataram que os encarregados realizam palestras, nas quais os mesmos são os apresentadores e procuram ensinar novos métodos de trabalho e aprimorar os que já estão sendo utilizados.

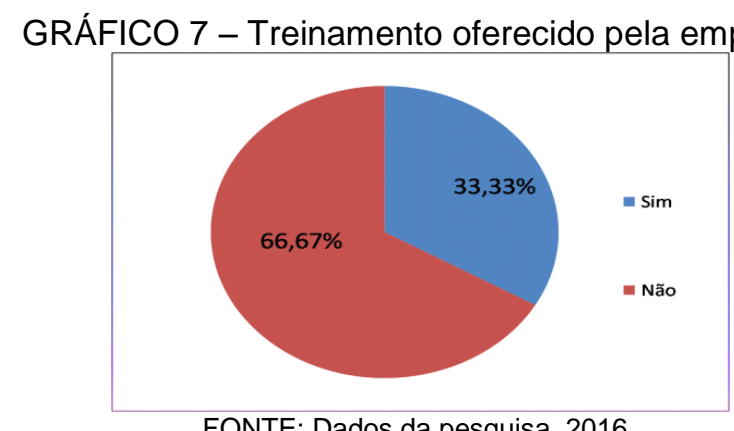


Outro dado bastante negativo foi que mais de $70 \%$ dos encarregados das obras, como pode ser evidenciado no gráfico 8 , não oferecem qualquer tipo de incentivo para que seus trabalhadores venham a participar dos programas de treinamentos ou cursos de reciclagens. Os $22,22 \%$ que falaram que recebiam incentivos, mencionaram que as empresas prometem a eles uma perspectiva de crescimento no cargo e, consequentemente, irão conduzir a melhores salários. Esses dados contradizem a visão de Faria (2011), que exalta que os principais pontos a serem atingidos em um treinamento são a formação profissional, a especialização e a reciclagem.

GRÁFICO 8 - Incentivo para participação em treinamentos, cursos e/ou reciclagem profissional

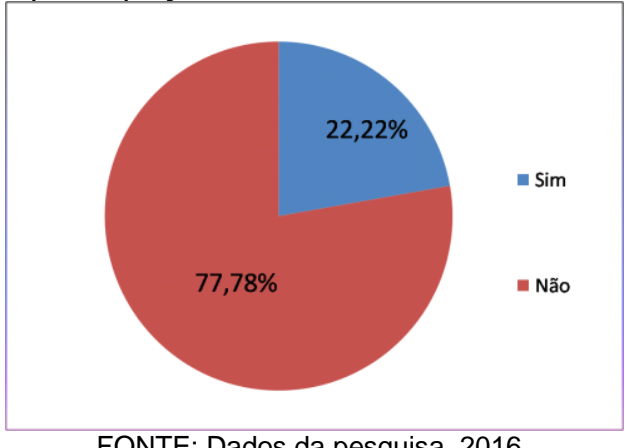

FONTE: Dados da pesquisa, 2016.

Dentro dos dados obtidos daquele pequeno grupo que já participou de algum tipo de treinamento, no gráfico 9 , observa-se que foi unânime a resposta de que o treinamento envolveu uma palestra com o encarregado da obra. Palestra essa que ocorre todas as segundas e sextas-feiras.

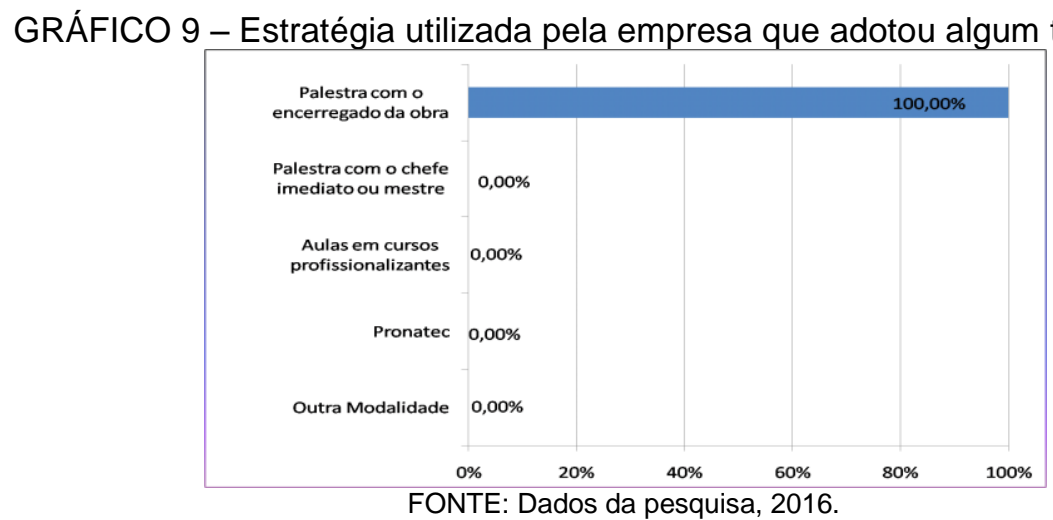

O último ponto abordado no questionário foi em relação aos benefícios no qual o treinamento pode trazer para a vida profissional deles e como foi observado no gráfico 10, que o aumento salarial foi o mais cobiçado pelos trabalhadores. Esse fato já era esperado, tendo em vista o resultado negativo no gráfico 2.

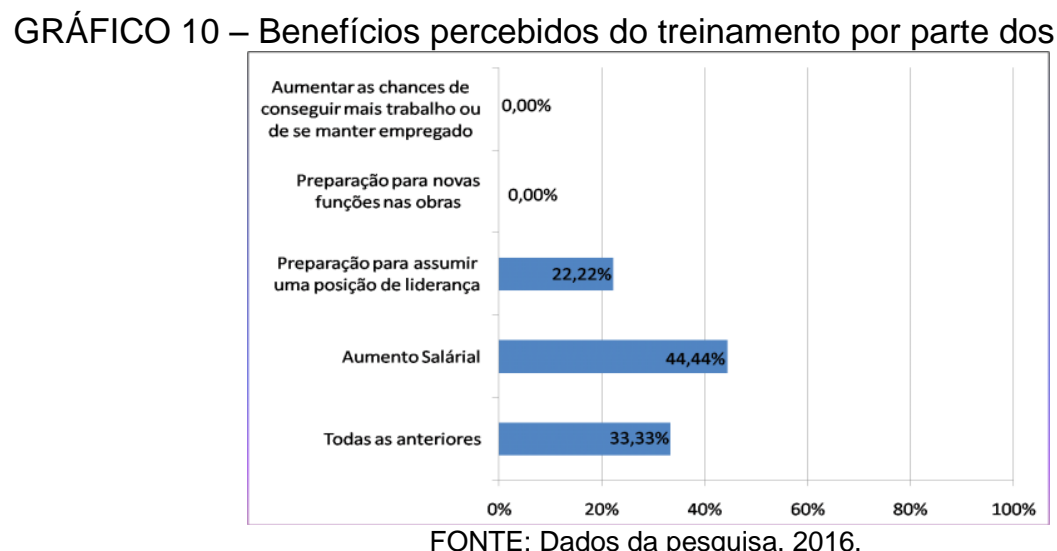




\subsection{Análise das entrevistas}

Após o uso de formulários com os trabalhadores das obras, passou-se a palavra aos responsáveis pelas mesmas. Na entrevista, os responsáveis falaram sobre como funcionava o processo de treinamento dos seus subordinados e sobre a importância que isso poderia trazer para o resultado final da obra.

O primeiro ponto analisado foi que apenas um dos três entrevistados exige algum tipo de treinamento de seus operários:

Sim. Todos eles para entrar aqui são treinados para começar a trabalhar. Todos com segurança, não podem entrar sem segurança, segurança é tudo, nós somos terceirizados. É tudo de alto nível aqui. O treinamento é fazer tudo do melhor. Não andar sem bota. Só pode entrar na obra quem trabalha. Quem não trabalha não entra, só entra quem trabalha mesmo. (Encarregado $\mathrm{X})$.

Não. (Encarregado Y).

Não, aqui é particular, obra residencial. (Encarregado Z).

Com base nas respostas acima, só o encarregado da obra $X$ segue o pensamento exposto por Carvalho, Nascimento e Serafim (2012) em que os mesmos defendem que o treinamento é uma das etapas finais do processo de seleção dos operários.

Outro ponto abordado foi em relação a quais seriam os tipos de treinamentos que a empresa utiliza para capacitar seus trabalhadores. Novamente, apenas um dos encarregados relatou que faz uso desse tipo de estratégia, os outros dois encarregados não fazem uso de treinamento no canteiro, eles relatam que seus trabalhadores não necessitam de treinamento em questão da vasta experiência em seus cargos:

Ai, ai... eles já... nem sei dizer. Eu já digo a eles direto, é uma coisa só toda vez, eles têm que seguir o jeito certo de trabalhar, não sair da linha. É no dia a dia, na segunda e na sexta, segunda e sextas têm treinamento, uma reunião seguindo a orientação do encarregado. Uma palestra para todos, reúnem todos. (Encarregado X).

Não. Geralmente a gente trabalha com operadores já capacitados ou pessoas que já trabalham há muito tempo, com experiência na construção. (Encarregado Y).

Nenhum. (Encarregado Z).

Milkovich e Boudreau (2013) afirmam que a realização de treinamento com os operários é um grande negócio para a empresa. Apenas o encarregado da obra X tem essa visão. Os encarregados das obras $\mathrm{Y}$ e Z se enquadram no contexto de que a desqualificação de mão de obra resulta diretamente da falta de interesse dos donos das organizações em realizar ações, como treinamentos, para garantir uma melhor produtividade e qualidade em suas obras (FARIA, 2011). Em decorrência da resposta anterior ter sido na maioria negativa, apenas o encarregado da obra $X$ relatou realiza o treinamento dos seus funcionários duas vezes por semana:

É toda segunda e na sexta eles têm uma orientação do encarregado. É uma palestra de 30 minutos com o encarregado, toda segunda e sexta. Duas vezes por semana, 30 minutos na segunda e 30 minutos na sexta. (Encarregado X).

Essa atitude diferencial do encarregado $X$ em relação aos outros encarregados tem uma visão positiva para Chiavenato (2009), quando o mesmo relata que as mudanças de atitudes criam um clima mais satisfatório. Quando abordados sobre quais incentivos eles oferecem aos seus trabalhadores, apenas o encarregado da obra $X$ oferecia incentivo aos seus subordinados, para que os mesmos participem de treinamentos de aprimoramento. Um dos entrevistados acredita que só em estar trabalhando e aprendendo, na prática, já é o treinamento necessário:

É assim: fazer o curso, procurar trabalhar melhor, não pode chegar bêbado, nem com ressaca e sempre melhorar. É de ajudante para passar para pedreiro, só crescendo... não é para ficar numa função só. Participando do treinamento, eles podem subir de cargo. Tem deles que rapidinho sobem de função, é no máximo seis meses para eles mudarem de função. (Encarregado X).

Nenhum. (Encarregado Y).

Não oferece porque a gente já tem o treinamento da prática, mas não tem nenhum treinamento não. (Encarregado Z). 
Carvalho, Nascimento e Serafim (2012) afirmam que o treinamento requer a adoção de metas e de resultados a serem alcançados pelos trabalhadores. $O$ encarregado da obra $X$ traça metas como incentivo para que seus subordinados cresçam dentro da obra.

O ponto mais interessante dessa entrevista se deu pelas respostas dadas pelos encarregados na quinta pergunta da entrevista, quando os mesmos foram abordados sobre os benefícios que o treinamento de mão de obra poderia trazer para o resultado final da obra:

De melhor a melhor. Nada para baixo, só para cima. (Encarregado X).

Acredito que o treinamento é essencial, mas, na cidade da gente, não tem esse tipo de treinamento, geralmente, mas se tivesse, com certeza, a obra seria mais rápida, mais segura e conduzida de uma forma melhor. (Encarregado Y).

Quanto mais aprender melhor. (Encarregado Z).

Notou-se que todos têm uma visão de que o treinamento é sempre positivo, mas nem todos implementam isso em suas obras. Eles não põem em prática o que eles sabem que funciona na teoria. Chiavenato (2010) expressa que, para serem bem-sucedidas, as organizações precisam de pessoas capazes, ágeis, dotadas de habilidades que são adquiridas com um bom treinamento.

O último ponto abordado foi em relação à forma que os encarregados utilizavam para promover e desligar seus operários:

Promoção: Não tem critério, ele cresce por ele mesmo. Depende do interesse dele.

Desligamento: Só por justa causa. Por exemplo, roubo de ferramenta, material, pegar briga ou confusão na obra. É justa causa, sai sem direito de nada. (Encarregado X).

Promoção: Dependendo do tipo de trabalho que ele exerça e seu desempenho, podendo ter um cargo a mais. Depende muito da pessoa. Tem gente que não tem interesse de subir de cargo não, mas têm pessoas que buscam e você vê isso e faz com que ele suba na profissão.

Desligamento: geralmente nesse ramo de construção não é a demissão dos trabalhadores, sempre a demissão acontece quando a gente termina o trabalho. Aqui como uma obra privada, a gente chama as pessoas para trabalhar até a finalização da obra. Não tem um critério, como uma empresa. É a obra, só essa obra e acabou. (Encarregado Y).

Promoção: Pagar bem a ele.

Desligamento: Ele dar mancada. O cara manda embora. (Encarregado Z).

Observa-se que os critérios de promoção estão relacionados ao desempenho do trabalhador dentro da obra. Já para o desligamento, fatores como ter uma conduta indesejada dentro da obra, ou quando seus serviços já não são mais desejados.

\subsection{Principais gargalos ao bom desempenho na construção civil}

Portanto, a partir do entendimento dessas diferenças, é possível entender como é a qualificação dos trabalhadores da construção civil e seu grau de valorização. Essa ideia é reforçada com o argumento de Moraes, 2006, p 45: "A lógica que se utiliza da qualificação profissional para estabelecer diferenças de remuneração também justifica a divisão do trabalho em intelectual e braçal, valorizando mais o primeiro em detrimento do segundo.

O mesmo, ainda relata que mesmo não executando funções intelectuais, os profissionais que executam trabalho braçal devem passar por uma preparação para suportar o trabalho pesado e desempenhar bem a sua função, tendo em vista que as empresas prezam pelo preparo tático desse tipo de profissional no canteiro de obras.

Dando ênfase à importância e à exigência de profissionais mais qualificados no mercado de trabalho da construção civil, Neves $(2014$, p. 7) defende: "Questões vinculadas à qualidade e produtividade são exigências do mundo atual com a construção civil. Os processos construtivos precisam demonstrar de forma expressiva sua eficiência, dinâmica e competência."

As diferenças apresentadas desses perfis induzem a uma diferença entre funções, salários e responsabilidades entre os profissionais. Para Moraes (2006), é notória a existência dessas diferenças, o mesmo divide os profissionais da construção em dois grandes grupos: os que executam o trabalho intelectual e os que executam o trabalho braçal, nas obras.

Com base nos dados, conclui-se que os profissionais de níveis mais elevados de escolaridade como engenheiros, arquitetos e tecnólogos estão engajados no grupo que executam os trabalhos intelectuais, que recebem melhores salários e profissionais com menos ou nenhum grau de escolaridade, como pedreiros e 
serventes, fazem parte da classe que executa o trabalho braçal, vindo a receber salários inferiores aos citados acima.

Essa ideia representada acima é reforçada por Souza (2006), enfatizando o raciocínio da teoria do capital humano, na qual pessoas que se educam aumentam suas habilidades e conhecimentos, aumentando, assim, sua produtividade e, dessa forma, tendem a receber maiores rendas.

\section{CONCLUSÕES}

O presente trabalho teve como objetivo avaliar o nível de treinamento dos trabalhadores da construção civil em Monteiro-PB.

Para conseguir alcançar seu objetivo geral, alguns objetivos específicos foram formulados. Com relação aos incentivos oferecidos pelas organizações para capacitação da sua força de trabalho, os resultados são desanimadores. Não existem políticas e práticas formais de estímulo à participação dos trabalhadores em cursos e treinamentos. Talvez esse fenômeno ocorra em função da falta de conhecimento da relação treinamento-desempenho, em virtude do baixo nível de profissionalização dos gestores e elevada informalidade.

Com relação à frequência a que os trabalhadores são submetidos a treinamentos, observou-se que a maioria dos trabalhadores não se submete a nenhum tipo de treinamento. Observou-se que, de maneira geral, a maior parte dos trabalhadores da construção civil na região não apresenta qualquer tipo de treinamento formal para o trabalho, sendo escassos os que possuem curso de formação.

Quanto às estratégias de treinamento utilizadas, observou-se a predominância de palestras em função de ser uma técnica simples e rápida. No entanto, em que pesem suas vantagens, deve-se levar em consideração o caráter altamente prático e técnico da tarefa executada pelos operários da construção. Cabe destacar que técnicas de treinamento que enfoquem os aspectos práticos da atividade profissional são necessárias ao bom desempenho do trabalho na construção civil, com reflexos positivos na redução de patologias e aumento da produtividade.

Um dado que chama a atenção é a predominância de trabalhadores do sexo masculino. No contexto da pesquisa, a totalidade dos trabalhadores eram homens.

Conclui-se que existe uma grande carência de uma política de capacitação e treinamento da força de trabalho na área de construção civil na região de Monteiro. Essa carência é consequência do baixo nível de profissionalização das construções, conduzidas por profissionais sem o devido preparo e que não dominam os princípios básicos da Administração de Recursos Humanos e não dão o devido valor ao capital humano, o grande ativo e maior diferencial competitivo das organizações da atualidade.

Como sugestões de estudos futuros, sugerem-se pesquisas que analisem essa realidade em outros contextos, como localidades maiores que apresentam maior volume de organizações e construções. Estudos que analisem os impactos da precarização do trabalho operário e seu nível de informalidade também serão relevantes, em função da elevada informalidade na área.

\section{REFERÊNCIAS}

ABBATE, Vinicius. Cenários de custos: Agentes do setor fazem suas apostas para o comportamento dos custos de materiais em 2010. Revista Construção Mercado Negócios de Incorporação e Construção, São Paulo, ano 63, n. 102, p. 26-28, jan. 2010.

ARAUJO, Diogo Ferreira de. Análise da viabilidade econômica de novos projetos. 2010. 119 f. Monografia (Mestrado Profissionalizante em Engenharia) - Universidade Federal do Rio Grande do Sul Escola de Engenharia, Rio de Janeiro. 2010.

ASSOCIAÇÃO BRASILEIRA DA INDÚSTRIA DE MATERIAIS DA CONSTRUÇÃO. Capacitação e certificação profissional na Construção Civil e mecanismos de mobilização da demanda: ABRAMAT. São Paulo, outubro de 2007. 130 p. e apêndices.

ASSOCIAÇÃO BRASILEIRA DE NORMAS TÉCNICAS. NBR 10015: Gestão da qualidade - diretrizes para treinamento. Rio de Janeiro, 2001.20 em<http://licenciadorambiental.com.br/wp-content/uploads/2015/01/NBR-ISO-10.015-Gest\%C3\%A3o-da-qualidade-diret rizes-para-treinamento.pdf>. Acesso em 16 de Mar. De 2016.

BARDIN, Laurence. Análise de conteúdo. São Paulo: Edições 70, 2011.

BELLEI, Carolina. Obras à vista: Crescimento da indústria naval impulsiona construção de estaleiros; até 11 novos de grande porte devem ser construídos nos próximos anos. Revista Construção Mercado Negócios de Incorporação e Construção, São Paulo, ano 63, n. 103, p. 18-19, fev. 2010.

BLANCO, Mirian. O preço da desqualificação: Em pleno crescimento do setor da construção, cerca de 112 mil vagas de trabalho foram abertas no último ano. Mas, com tantos anos sem investir na qualificação da mão-de-obra, o mercado já 
sente falta de braços bem treinados para tocar as novas obras. Construção mercado, São Paulo, ago. 2007. Disponível em: <https:construcaomercado.pini.com.br/negócios-incorporacao-construcao/73/artigo282069-1.aspx>. Acesso em: 12 jan. 2016.

CARVALHO, Antonio Vieira de; NASCIMENTO, Luiz Paulo do; SERAFIM, OziléaClen Gomes. Administração de Recursos Humanos. 2. ed. Rev. São Paulo: Cengage Learning, 2012.

CATELLI, Armando. Controladoria: Uma abordagem da gestão econômica. 2. ed. São Paulo: Atlas, 2001.

CHIAVENATO, Idalberto. Recursos Humanos - O Capital Humano das Organizações. 9. ed. Rio de Janeiro: Elsevier, 2009.

Gestão de Pessoas - O Novo Papel dos Recursos Humanos nas Organizações. 3. ed. Rio de Janeiro: Elsevier, 2010.

CICHINELLI, Gisele C.; REIS, Pâmela. Mapa de escassez: Liderança setoriais traçam o panorama de falta de mão de obra nos estados e apontam ações para superá-la. Revista Construção Mercado Negócios de Incorporação e Construção, São Paulo, ano 63, n. 103, p. 29-31, fev. 2010.

COLLETTI, J. C. PIB - Produto Interno Bruto. 2006. Disponível em:< http://www.administradores.com.br/informe-se/artigos/pib-produto-internobruto/12962/ >. Acesso em: 08 fev. 2016.

FARIA, Daniel Dias. CAPACITAÇÃo DA MÃO-DE-OBRA E A EFICÁCIA DO TREINAMENTO VISUAL. 2011.41 f.Monografia (Graduação em Engenharia Civil) - Universidade Federal de Fortaleza, Fortaleza. 2011.

FERREIRA JUNIOR, Cláudio Barboza. Diretrizes para a capacitação profissional por competências de trabalhadores da construção civil. 2012. 100 f. Dissertação (Mestrado em Engenharia) - Escola Politécnica da Universidade de São Paulo, São Paulo. 2012.

FRANÇA, Alessandra A. V., et al. Patologia das construções: uma especialidade na engenharia civil. techne.pini, São

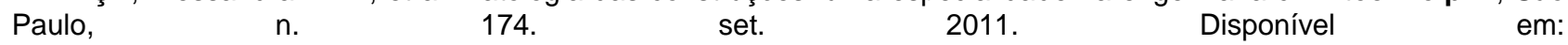
$<$ http://techne.pini.com.br/engenharia-civil/174/patologia-das-construcoes-uma-especialidade-na-engenharia-civil-28589 2-1.aspx>. Acesso em: 12 mar. 2016.

IBGE. INSTITUTO BRASILEIRO DE GEOGRAFIA E ESTATISTICA. Disponível em<ftp://ftp.ibge.gov.br/Industria_da_Construcao/Pesquisa_Anual_da_Industria_da_Construcao/2010/comentario.pdf> Acesso em: 16 mar. 2016.

IBGE ESTADOS. INSTITUTO BRASILEIRO DE GEOGRAFIA E ESTATISTICA. Disponível em: $<$ http://www.ibge.gov.br/estadosat/perfil.php?sigla=pb>. Acesso em: 16 mar. 2016.

LIMMER, C. V. Planejamento, Orçamentação e controle de projetos e obras.1. ed. Rio de Janeiro: LTC. 2010.

MENDES, Gustavo. Procuram-se operários: O diagnóstico da falta de mão de obra na construção e os caminhos para enfrentar o problema. Revista Construção Mercado - Negócios de incorporação e construção, São Paulo, ano 63, n. 103, p. 26-31, fev. 2010.

MERCARDO DE TRABALHO DA CONSTRUÇÃO CIVIL - CIBIC, 2010. CAMARA BRASILEIRA DA INDÚSTRIA DA CONSTRUÇÃO.

Disponível

em: <http://www.cbic.org.br/sala-de-imprensa/apresentacoes-estudos/o-mercado-de-trabalhao-da-construcao-civil>. Acesso em: 01 de dez. 2015.

MCKINSEY GLOBAL INSTITUTE. Produtividade: a chave do desenvolvimento acelerado no Brasil. São Paulo, McKinsey Brasil, mar. 1998. (Relatório).

MILKOVICH, George T.; BOUDREAU, John W. Administração de Recursos Humanos. 1. ed. São Paulo: Atlas, 2013.

MORAES, Eduardo Rodrigues de. O valor social do trabalho e da formação humana: a dimensão político-pedagógica do exercício profissional na construção civil. 2006. 117 f. Dissertação (Mestrado em Educação).- Universidade Federal do Paraná, Curitiba. 2006.

NEVES, Suzana Andreassa. A qualificação da mão de obra para o aumento da produtividade em obras de construção civil: responsabilidades compartilhadas. 2014. 124 f. Dissertação (Mestrado em Engenharia Civil)Universidade Tecnológica Federal do Paraná, Curitiba. 2014.

OLIVEIRA, Daniel Ferreira. Levantamento de Causas de Patologias na Construção Civil. 2013. 97 f. Monografia (Graduação) - Universidade Federal do Rio de Janeiro, Rio de Janeiro, 2013.

PASSOS, Anselmo Galvãoet al. Análise estatística da evolução do produto interno bruto da indústria da construção civil brasileira utilizando regressão linear simples. Em Pauta - Revista GEINTEC - Gestão, Inovação e Tecnologias, Sergipe, v. 2, n. 5, p. 505-514, 2012.

REGINO, Gabriel. Como qualificar a mão de obra na construção civil: Metodologia para atualização profissional no canteiro de obra.1. ed.,São Paulo:PINI, 2010.

SAMARCOS, Moacyr Ramos et al. Educação profissional: Referencias Curriculares Nacionais da Educação Profissional de nível Técnico.ed. Brasilia: 2000.

SECRETARIA DA RECEITA FEDERAL DO BRASIL - MINISTERIO DA FAZENDA. Disponível em: <http://www.receita.fazenda.gov.br/previdencia/ConstrCivil.htm>. Acesso em: 12 dez. 2015.

SEEWALD, Silvia. A mão e a mente que fazem a obra: proposta de programa de treinamento de trabalhadores da 
construção civil em segurança no trabalho. 2004. 119 f. TCC (Mestrado Profissionalizante em Engenharia) - Universidade Federal do Rio Grande do Sul, Porto Alegre. 2004.

SOUZA, Ubiraci Espinelli Lemes de. Como Reduzir Perdas no Canteiros: Manual de gestão do consumo de materiais na construção civil. São Paulo: PINI, 2005.

Como aumentar a eficiência da mão-de-obra: Manual de gestão da produtividade na construção civil. São Paulo: PINI, 2006.

SOUZA, Marcos Ferreira de. Patologias ocasionadas pela umidade nas edificações. Monografia (Especialista)-Universidade Federal de Minas Gerais, Belo Horizonte, 2008.

SOUZA, Vicente Custódio Moreira de; RIPPER, Thomaz. Patologia, recuperação e reforço de estruturas de concreto. 1. ed. São Paulo: PINI, 2009. 
